\title{
Pollution characteristics of volatile organic compounds emitted from penicillin fermentation workshop

\author{
Bin Guo ${ }^{*}, 1$, , Ruijing Yao, ${ }^{1, b}$, Zhao Du ${ }^{1}$, Shuo Zhang ${ }^{1}$, \\ Hui Kang ${ }^{1}$ and Shanshan Wang ${ }^{1}$
}

School of Environmental Science and Engineering, Hebei University of Science and Technology;

Hebei Research \& Development Center for Air Pollution Prevention and Control, China.

Shijiazhuang 050018, China

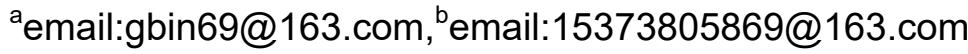

Corresponding Author: Bin Guo

Keywords: Fermentation exhaust, VOCs, GC/MS instrument, Pollution characteristics

\begin{abstract}
The air samples in two different stages (high temperature sterilization stage and fermentation stage) of penicillin fermentation workshop were sampled in fermentation process to investigate the pollution level of VOCs in fermentation exhaust. Results showed that the staggered variation of VOCs in penicillin fermentation workshop was obvious. The concentration of VOCs in high temperature sterilization stage was higher than that in fermentation stage. The concentration of VOCs was relatively high in high temperature sterilization stage, which might be caused by the evaporation of contamination in high temperature. Chlorinated hydrocarbons were found as the major component emitted from the penicillin fermentation workshop, while ester compounds were mainly emitted from the holding phase of the high temperature sterilization phase. In the 23detected VOCs in high temperature sterilization stage, while in fermentation stage only detected VOCs in 15 , the concentration of trichlorotrifluoroethane, dichlorotetrafluoroethane, 1,1-dichloroethene and vinyl acetate was relatively high in fermentation process.
\end{abstract}

\section{Introduction}

Volatile organic compounds (VOCs) is widespread in the air and the source of a class of complex organic pollutants, the main ingredients for hydrocarbon, hydrocarbon oxygen, nitrogen containing halogen hydrocarbon, hydrocarbon and sulfur hydrocarbons, polycyclic aromatic hydrocarbon of low boiling point, etc.) in the atmosphere are emitted from both biogenic (mainly from vegetation) and anthropogenic sources (e.g. vehicular and fossil-fueled power plant emission and solvent usage $)^{[1-4]}$. Emissions of VOCs are becoming one of the most stringent environmental challenges in many industrial processes. VOCs adversely affect the ground air quality, which in turn poses detrimental effects on human health, plants and vegetation. VOCs are also precursor to the formation of ozone ${ }^{[5]}$, an irritant at low concentration levels and a primary component of smog. The formation of ozone in the troposphere as a consequence of the photochemical reactions of VOCs with atmospheric nitrogen oxides $(\mathrm{NOx})$ is well-understood ${ }^{[6,7]}$. With the speeding up of urbanization in our country, the pollution problem of the VOCs in the atmosphere is more outstanding, some large and medium-sized cities in our country of VOCs in the air of concentration is higher, the cities and key industrial regional atmospheric environmental impact, VOCs emission characteristics of research has been more and more attention ${ }^{[8-10]}$.

The pharmaceutical industry, which has serious foul odor pollution problems, is one of the important industrial pollution sources for VOCs. Penicillin production process through microbial anaerobic fermentation generates a large amount of VOCs from fermentation. Recently, a few studies on the pollution characteristics of VOCs in the field of waste water, soil and industrial production, etc. were reported. However, the characteristics of VOCs emission from fermentation tail gas remain unclear ${ }^{[11]}$.

Herein, in this paper, penicillin fermentation exhaust was selected as the research object, and the 
composition and pollution characteristics of fermentation exhaust at different stages of penicillin fermentation process were investigated. Moreover, VOCs emission standard of pharmaceutical industry were established.

\section{Materials and methods}

\subsection{Sampling sites.}

The penicillin fermentation process can generally be divided into two stages: high temperature sterilization stage and fermentation stage. Sampling site is located in the bypass orifice of fermentation tank which is a strong source of emissions, which has representative for VOCs overall average of penicillin fermentation exhaust during sterilization stage; In addition, the exhaust gas from normal fermentation stage was collected at the outlet of the height of $15 \mathrm{~m}$ chimney.

\subsection{Analytical methods.}

The compositions of VOCs samples were qualitatively and quantitatively analyzed by preconcentrator (7100, Entech Instruments, USA) and GC-MS (7890A GC-5975C MS, Agilent, USA) combined techniques with the USEPA TO-15 method ${ }^{[12,13]}$. ADB-1 column $(60 \mathrm{~m} \times 0.32 \mathrm{~mm} \times 0.25 \mu \mathrm{m}$, Agilent, USA) was used with the GC oven temperature program: initially $40{ }^{\circ} \mathrm{C}$ for $5 \mathrm{~min}$, programmed to $120{ }^{\circ} \mathrm{C}$ at a rate of $5{ }^{\circ} \mathrm{C} \cdot \mathrm{min}-1$, and then to $180{ }^{\circ} \mathrm{C}$ at a rate of $10{ }^{\circ} \mathrm{C} \cdot \mathrm{min}-1$ which was held for $2 \mathrm{~min}$, programmed to $260^{\circ} \mathrm{C}$ at a rate of $15{ }^{\circ} \mathrm{C} \cdot \mathrm{min}-1$. Mass spectrometer conditions were as follows: temperature of the transfer line is $280^{\circ} \mathrm{C}$, ionizing energy is $70 \mathrm{ev}$ and scan range is $30-450 \mathrm{~m} \cdot \mathrm{e}^{-1}$. The concentrations of the most VOCs were quantified by external standard calibration which was determined by standard samples of TO-15 (Linde Spectra Environment Gases, USA).

\subsection{Quality control and assurance}

Before sampling, all Summa canisters were flushed at least five times by repeatedly filling and evacuating with high purity nitrogen. External standard method analyzes samples qualitatively and quantitatively. Lab blank samples and duplicate samples were analyzed by the same method,that can ensure the precision and accuracy of the experimental results ${ }^{[14]}$.

\section{Results and discussion}

\subsection{Compositions of fermentation exhaust.}

During penicillin fermentation process, only the high temperature sterilization and fermentation stages have the potential to release VOCs. Hence, the characteristics of VOCs emissions from these two different stages were investigated. A total of eight groups including 23 kinds of VOCs were identified and quantified. Fermentation exhaust at high temperature sterilization and fermentation stages contained 13 kinds of the same VOCs which are as follows: benzene, carbon tetrachloride, 1,3-butadiene, ethenyl ethanoate, methyl chloride, methylene chloride, toluene, ethylbenzene, o-xylene, m-xylene, p-xylene, styrene, trifluorotrichloroethane. As shown in Table 1, in the heating, holding and cooling stage during sterilization process, VOCs species are almost the same. In the 23 detected VOCs in high temperature sterilization stage, while in fermentation stage only detected VOCs in 15. During the fermentation process, the pollutants with concentration higher than 100 $\mathrm{mg} \cdot \mathrm{m}^{-3}$ are vinyl acetate, trifluorotrichloroethane, dichlorotetrafluoroethane, 1,1-dichloroethylene. The concentration of total VOCs (TVOC) in the heating period of high temperature sterilization stage $\left(5.42 \times 10^{3} \mathrm{mg} \cdot \mathrm{m}^{-3}\right)$ is much higher than that in the fermentation stage $\left(2.02 \times 10^{2} \mathrm{mg} \cdot \mathrm{m}^{-3}\right)$. This result may be related to the high temperature during sterilization stage which contributed to the volatilization of VOCs. 
Table 1 The mass concentration of VOCs in the tail gas of penicillin fermentation

\begin{tabular}{|c|c|c|c|c|c|}
\hline \multirow{2}{*}{ Serial number } & \multirow{2}{*}{$\begin{array}{c}\text { Target } \\
\text { compounds }\end{array}$} & \multicolumn{4}{|c|}{ Concentration $\left(\mathrm{mg} \cdot \mathrm{m}^{-3}\right)$} \\
\hline & & Heating stage & Holding stage & Cooling stage & Fermentation stage \\
\hline 1 & Benzene & 1.20 & 0.77 & 0.73 & 0.41 \\
\hline 2 & Carbon tetrachloride & 0.73 & 0.30 & 0.30 & 0.45 \\
\hline 3 & Cyclohexane & 22.67 & 4.65 & 0.45 & N,D \\
\hline 5 & Ethanol & 32.64 & 7.51 & 17.39 & N,D \\
\hline 6 & 1, 3-Butadiene & 4.76 & 3.61 & 18.02 & 1.67 \\
\hline 7 & Vinyl acetate & 1266.48 & 322.20 & 122.68 & 51.45 \\
\hline 8 & Carbon disulfide & 140.47 & 25.19 & 1.45 & N,D \\
\hline 9 & Hexane & 0.02 & 37.08 & 60.07 & N,D \\
\hline 10 & THF/2-Butanone ${ }^{(2)}$ & 35.77 & 60.99 & $\mathrm{~N}, \mathrm{D}$ & $\mathrm{N}, \mathrm{D}$ \\
\hline 11 & $\begin{array}{l}\text { Dichlorotetrafluoroethan } \\
\mathrm{e}\end{array}$ & 544.45 & 51.30 & 526.20 & N,D \\
\hline 12 & Methyl chloride & 27.77 & 11.65 & 18.70 & 0.24 \\
\hline 13 & 1.2.4-Trimethylbenzene & 0.06 & $\mathrm{~N}, \mathrm{D}^{(1)}$ & $\mathrm{N}, \mathrm{D}$ & 0.02 \\
\hline 14 & Styrene & 0.29 & 0.13 & 0.17 & 0.34 \\
\hline 15 & o-Xylene & 0.85 & 0.25 & 0.59 & 0.69 \\
\hline 16 & Paraxylene & 0.86 & 0.25 & 0.59 & 0.70 \\
\hline 17 & m-Xylene & 0.29 & 0.13 & 0.17 & 0.28 \\
\hline 18 & Ethyl benzene & 0.24 & 0.15 & 0.26 & 0.17 \\
\hline 19 & Toluene & 1.14 & 0.55 & 0.68 & 0.53 \\
\hline 20 & Chloroform & 1.25 & $\mathrm{~N}, \mathrm{D}$ & 0.17 & 0.14 \\
\hline 21 & Dichloromethane & 17.42 & 5.32 & 5.02 & 6.94 \\
\hline 22 & Trifluorotrichloroethane & 1622.74 & 6.45 & 316.46 & 137.96 \\
\hline 23 & 1,1-Dichloroethylene & 1363.87 & 76.45 & $\mathrm{~N}, \mathrm{D}$ & N,D \\
\hline The & total of VOCs & 5416.43 & 614.93 & 1099.64 & 201.97 \\
\hline
\end{tabular}

Note: 1) N,D said not detected; 2) because of tetrahydrofuran and 2-butanone in this institute on chromatographic column cannot be separated,so the tetrahydrofuran and 2-butanone columns together.

\subsection{Contribution of fermentation exhaust.}

As mentioned above, pollutants in fermentation exhaust can be divided into eight categories by functional groups, which are as follows: chlorinated hydrocarbon, naphthenes, aromatic hydrocarbons, ketone, low molecular glucosinolates content, esters, olefin and alcohol. From table 2, the proportion of chlorinated hydrocarbons at heating stage, cooling stage and fermentation stage ris $66.06 \%, 78.83 \%, 72.15 \%$, respectively. At these three stages, chlorinated hydrocarbons is main pollutant with the highest concentrations of VOCs. Nevertheless, the proportion of ester at four stages of fermentation process is $23.38 \%, 52.40 \%, 11.16 \%, 25.47 \%$. The highest proportion $(52.40 \%)$ of esters appeared in the holding stage. The content of these two kinds of pollutants combined account for more than $90 \%$ of TVOCs. While the proportion of aromatic hydrocarbons is only $1.55 \%$, which is different with other relevant literature.However, why would a large number of chlorinated hydrocarbons in the fermentation exhaust gas, needed the next phase of research.

Theories and data are supplied to resolve the problems in penicillin fermentation exhaust. So, we can make the treatment measures with chlorinated hydrocarbons and esters for fermentation exhaust. 
Table 2 Contribution of VOCs with different functional groups

\begin{tabular}{|c|c|c|c|c|c|}
\hline \multirow{2}{*}{$\begin{array}{c}\text { Serial } \\
\text { number }\end{array}$} & \multirow{2}{*}{$\begin{array}{c}\text { Types } \\
\text { Of VOCs }\end{array}$} & \multicolumn{4}{|c|}{ Proportion $(\%)$} \\
\hline & & $\begin{array}{c}\text { heating } \\
\text { stage }\end{array}$ & $\begin{array}{l}\text { holding } \\
\text { stage }\end{array}$ & $\begin{array}{l}\text { cooling } \\
\text { stage }\end{array}$ & $\begin{array}{c}\text { fermentation } \\
\text { stage }\end{array}$ \\
\hline 1 & Naphthene & 0.42 & 6.79 & 5.50 & 0.00 \\
\hline 2 & Alcohol & 0.60 & 1.22 & 1.58 & 0.00 \\
\hline 3 & Olefin & 0.09 & 0.59 & 1.64 & 0.83 \\
\hline 4 & Esters & 23.38 & 52.40 & 11.16 & 25.47 \\
\hline 5 & Low molecular sulfide & 2.59 & 4.10 & 0.13 & 0.00 \\
\hline 6 & Ketone & 0.66 & 9.92 & 0.00 & 0.00 \\
\hline 7 & Naphthenes & 0.09 & 0.36 & 0.29 & 1.55 \\
\hline 8 & Chlorinated hydrocarbon & 66.06 & 24.63 & 78.83 & 72.15 \\
\hline
\end{tabular}

\section{Conclusions}

This study showed that the pollution characteristics of penicillin fermentation exhaust. A total of eight groups (Chlorinated hydrocarbon, naphthenes, aromatic hydrocarbons, ketone, low molecular sulfide, esters, olefinand alcohol) including $23 \mathrm{kinds}$ of VOCs were identified and quantified.The concentration range of TVOCs is $201.97 \mathrm{mg} \cdot \mathrm{m}^{-3}$ to $5416.43 \mathrm{mg} \cdot \mathrm{m}^{-3}$. The highest TVOCs concentration was observed in the heating time of the high temperature sterilization stage, and the least concentration of total VOCs (TVOC) is occurred in the fermentation stage. Chlorinated hydrocarbons were found as the major component emitted from the penicillin fermentation workshop, while ester compounds were mainly emitted from the holding phase of the high temperature sterilization phase. The main materials of chlorinated hydrocarbons and esters are trifluorotrichloroethane, tetrafluorodichloroethane, 1,1-dichloroethylene and vinyl acetate, respectively, which are the four most abundant VOCs. The content of these two kinds of pollutants combined account for more than $90 \%$ of TVOCs. Chlorinated hydrocarbons and esters can be used as the primary pollutants for VOCs control research.

\section{Acknowledgment}

This work was financially supported by the National Science-technology Support Plan Project of China (Project No.2014BAC23B04-03)

\section{References}

[1]. Huang,Y., Ling, Zh. H., Characterization of volatile organic compounds at a roadside environment in Hong Kong: an investigation of influences after air pollution control strategies. Atmospheric Environment. 122(2015): 809-818.

[2]. Atkinson R., Atmospheric chemistry of VOCs and NOx. Atmos.Environ. 2003.34,2063-2101.

[3]. Atkinson R., Arey, J., Atmospheric degradation of volatile organic compounds. Chemical Reviews. , 103(2003): 4605-4638.

[4]. Barletta, B., Meinardi, S., Rowland, F.S., et al, Volatile organic compounds in 43 Chinese cities. Atmospheric Environment. 39(2005): 5979-5990.

[5]. Qin, H., Li,J. J., Dynamic adsorption of volatile organic compounds on organofunctionalized SBA-15 materials. Chemical Engineering Journal. 149(2009): 281-288.

[6]. Gupta, V.K., Verma, N., Removal of volatile organic compounds by cryogenic condensation followed by adsorption. Chemical Engineering Science.,57(2002): 2679-2696.

[7]. Seinfeld, J., Atmospheric chemistry and physics of air pollution. New York: Wiley.1999. 
[8]. Liu Y.T., Peng, Y., Bai, Zh. P., et al, Characterization of Atmospheric Volatile Organic Compounds in Shenyang, China. Engineering Science. 32(2011,): 2777-2785.

[9]. Liu, Z.C., Zhang, F., Hou, L.J., et al, Pollution Characteristics of VOCs in Ambient Air of Ji'nan City in Summer. Engineering Science. 33(2012): 3656-3661.

[10]. He, L.Y., Lu, S.H., Feng, N., et al, Variation characteristics and chemical reactivity of ambient VOCs in Shenzhen. China Environmental Science, 33(2013): 808-813.

[11]. Guo, B., Song, Y., Lyv, G.L., et al, Pollution analysis and health risk assessment of volatile organic compounds from dense pharmaceutical production areas. Environment Chemistry. 33(2014):1354-1360.

[12]. He, Z.G., Li, J.J., Chen, J.Y., et al, Treatment of organic waste gas in a paint plant by combined technique of biotrickling filtration with photocatalytic oxidation. Chemical Engineering Journal. 200(2012): 645-653.

[13]. U.S. EPA, Compendium of Methods for the Determination of Toxic Organic Compounds in Ambient Air. Second edition. Centre for Environmental Information, Office of Research and Development.1999.

[14]. Wei, E.Q., Wang, Y.L., Shi, T.R., Study on the pollution characteristic of VOCs in ambient air of Anshan. Environmental Pollution \& Control. 33(2011): 61-65+70. 